\title{
Size-Selective Urea-Containing Metal-Organic Frameworks as Receptors for Anions
}

\author{
Leili Esrafili, ${ }^{a}$ Ali Morsali, ${ }^{* a}$ Mao-Lin Hu ${ }^{*}$, Alireza Azhdari Tehrani, ${ }^{a}$ Lucia Carlucci, ${ }^{c}$ Pierluigi \\ Mercandelli $^{c}$ and Davide M. Proserpio ${ }^{c, d}$ \\ ${ }^{a}$ Department of Chemistry, Faculty of Sciences, Tarbiat Modares University, P.O. Box 14115-175, \\ Tehran, Iran \\ ${ }^{b}$ College of Chemistry and Materials Engineering, Wenzhou University, Wenzhou 325035, P. R. \\ China \\ cDipartimento di Chimica, Università degli Studi di Milano, Milano 20133, Italy \\ ${ }^{d}$ Samara Center for Theoretical Materials Science (SCTMS), Samara State Technical University, Samara \\ 443100, Russia
}

\begin{abstract}
Materials and Physical Techniques. All starting materials, including zinc nitrate hexahydrate, 1,1'carbonyldiimidazole, 4-aminobenzoic acid and 4-aminopyridine were purchased from Aldrich and Merck and used as received. IR spectra were recorded using Thermo Nicolet IR 100 FT-IR. The thermal behaviour was measured with a PL-STA 1500 apparatus with a rate of $10^{\circ} \mathrm{C} \mathrm{min}^{-1}$ in a static atmosphere of nitrogen. X-ray powder diffraction (PXRD) measurements were performed using a Philips X'pert diffractometer with monochromated $\mathrm{Cu}-\mathrm{K \alpha}$ radiation. Diffuse reflectance spectroscopy (DRS) and solid-state photoluminescence were performed using an AvaSpec-2048TEC spectrometer. Fluorescence properties in solution were measured at room temperature on a Perkin Elmer-LS55 Fluorescence Spectrometer.
\end{abstract}

Many of anions, such as nitrate and fluoride are necessary for living organisms, and the human body, whereas in large quantities, the same elements are toxic. Some anions such as arsenate show extreme toxicity even at low concentrations Repeated or single exposure target organ/systemic toxicity refers to substances that can trigger organ-specific toxicity effects.

Synthesis of the Ligand L2. 4-Aminopyridine (0.941 g, $10 \mathrm{mmol})$ was dissolved in $25 \mathrm{~mL}$ of dry THF. To this solution, 1,1'-carbonyldiimidazole $(0.970 \mathrm{~g}, 6 \mathrm{mmol})$ was added. The mixture was refluxed under argon atmosphere overnight. The mixture was cooled to room temperature and the solvent was removed in vacuo. The resulting residue was taken up in brine and washed several times with distilled water and dried in vacuo to give a white precipitate. 


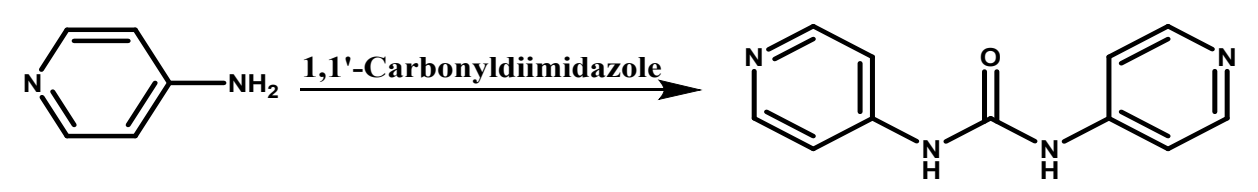

Spectroscopic data. FT-IR (KBr pellet, cm-1): 3394-2938 (vs), 2490 (m), 2283 (w), 2221 (m), 1734 (s), 1591 (vs), 1505 (vs), 1420 (m), 1331 (m), 1283 (s), 1188 (vs), 1000 (m), 826(s), 732 (w), 524 (w). Anal. calcd for $\mathrm{C}_{11} \mathrm{H}_{10} \mathrm{~N}_{4} \mathrm{O}$ : C 61.67, H 4.71, N 26.15. Found: C 60.58, H 4.64, N 26.28. MS (m/z): $214.10\left(\mathrm{M}^{+}\right.$, base peak). ${ }^{1} \mathrm{H}-\mathrm{NMR}\left(\mathrm{d}_{6}\right.$-DMSO) 9.29 (2H, s), 8.37-8.38 (4H, d), 7.43-7.44 (4H, d).

Crystal Structure Analysis. Single-crystal X-ray diffraction data for the metal-organic frameworks TMU67 and TMU-68 were collected on a Bruker APEX II CCD area detector diffractometer, using graphitemonochromated Mo $K \alpha$ radiation $(\lambda=0.71073 \AA)$. Data collection was performed at $150 \mathrm{~K}$. A full sphere of reciprocal space was scanned by $0.5^{\circ} \omega$ step, collecting 1440 frames in four different regions of the reciprocal space. After integration, an empirical absorption correction was made on the basis of the symmetry-equivalent reflection intensities measured.

The structures were solved by direct methods (SIR 2014) ${ }^{1}$ and subsequent Fourier synthesis; they were refined by full-matrix least-squares on $F^{2}$ (SHELX 2014) $)^{2}$ using all reflections. Weights were assigned to individual observations according to the formula $w=1 /\left[\sigma^{2}\left(F_{\mathrm{o}}^{2}\right)+(a P)^{2}+b P\right]$, where $P=\left(F_{\mathrm{o}}^{2}+2 F_{\mathrm{c}}{ }^{2}\right) / 3 ; a$ and $b$ were chosen to give a flat analysis of variance in terms of $F_{\mathrm{o}}^{2}$. Anisotropic parameters were assigned to all non-hydrogen atoms (except those of the disordered dimethylformamide molecules in TMU-67). All the hydrogen atoms were clearly visible in difference-Fourier maps (except those of the disordered dimethylformamide molecules in TMU-67); however, they were eventually placed in idealized position and refined riding on their parent atom with an isotropic displacement parameter 1.2 (or 1.5) times that of the pertinent parent atom.

In the structure of TMU-67 the solvate dimethyformamide molecule is disordered over two positions, possibly due to the large volume $\left(122 \AA^{3}\right)$ of the cavity occupied. The two overlapping images were refined applying soft restraints on bond distances and bond angles, based on the mean values obtained from a survey of the Cambridge Structural Database, employing isotropic parameters for all the atoms. Any attempt to refine the solvent molecule employing anisotropic displacement parameters leads only to negligible improvements in the $R$ factors at the expense of a significant increase in the number of refined parameters and in their correlation, and has been therefore discarded.

The final difference electron density map showed no features of chemical significance, with the largest peaks lying close to the metal atoms. 
Crystal data, data collection and refinement details of the structural analyses are summarized in Table S1, while a selection of geometric parameters for the two metal-organic frameworks are collected in Tables S2 and S3.

CCDC 2003540-2003541 contain the supplementary crystallographic data for TMU-67 and TMU-68. These data can be obtained free of charge via http://www.ccdc.cam.ac.uk/conts/retrieving.html, or from the Cambridge Crystallographic Data Centre, 12 Union Road, Cambridge CB2 1EZ, UK; fax: (+44) 1223-336033; or e-mail: deposit@,ccdc.cam.ac.uk. 
Table S1. Crystal data, data collection and refinement details for the metal-organic frameworks TMU-67 and TMU-68

$[\mathrm{Zn}(\mathrm{bpdc})(\mathrm{L} 2)]_{n} \cdot n \mathrm{DMF}(\mathbf{T M U}-67) \quad\left[\mathrm{Zn}_{2}(\mathrm{bdc})_{2}(\mathrm{~L} 2)_{2}\right]_{n} \cdot 2 n \mathrm{DMF}(\mathbf{T M U}-68)$

\begin{tabular}{|c|c|c|}
\hline \multicolumn{3}{|l|}{ Crystal data } \\
\hline Chemical formula & $\begin{array}{l}\mathrm{C}_{25} \mathrm{H}_{18} \mathrm{~N}_{4} \mathrm{O}_{5} \mathrm{Zn} \cdot \mathrm{C}_{3} \mathrm{H}_{7} \mathrm{NO} \\
=\mathrm{C}_{28} \mathrm{H}_{25} \mathrm{~N}_{5} \mathrm{O}_{6} \mathrm{Zn}\end{array}$ & $\begin{array}{l}\mathrm{C}_{19} \mathrm{H}_{14} \mathrm{~N}_{4} \mathrm{O}_{5} \mathrm{Zn} \cdot \mathrm{C}_{3} \mathrm{H}_{7} \mathrm{NO} \\
=\mathrm{C}_{22} \mathrm{H}_{21} \mathrm{~N}_{5} \mathrm{O}_{6} \mathrm{Zn}\end{array}$ \\
\hline$M_{\mathrm{r}}$ & 592.90 & 516.81 \\
\hline Crystal system & monoclinic & monoclinic \\
\hline Space group & $P 2_{1} / c$ (No. 14$)$ & $C 2 / c$ (No. 15) \\
\hline Temperature $[\mathrm{K}]$ & $150(2)$ & $150(2)$ \\
\hline$a[\AA]$ & $10.7550(7)$ & $17.4144(14)$ \\
\hline$b[\AA]$ & $21.0445(14)$ & $10.6579(9)$ \\
\hline$c[\AA]$ & $11.9923(8)$ & 23.8004(19) \\
\hline$\alpha\left[^{\circ}\right]$ & 90 & 90 \\
\hline$\beta\left[^{\circ}\right]$ & $99.7900(10)$ & $91.2380(10)$ \\
\hline$\gamma\left[^{\circ}\right]$ & 90 & 90 \\
\hline$V\left[\AA^{3}\right]$ & 2674.7(3) & $4416.3(6)$ \\
\hline$Z$ & 4 & 8 \\
\hline$\mu(\mathrm{MoK} \alpha)\left[\mathrm{mm}^{-1}\right]$ & 0.971 & 1.163 \\
\hline Crystal size $[\mathrm{mm}]$ & $0.300 \times 0.300 \times 0.300$ & $0.200 \times 0.200 \times 0.120$ \\
\hline \multicolumn{3}{|l|}{ Data collection } \\
\hline$T_{\min }, T_{\max }$ & $0.706,0.759$ & $0.748,0.873$ \\
\hline No. of measured reflections & 51021 & 32936 \\
\hline No. of independent reflections & 8572 & 6949 \\
\hline $\begin{array}{l}\text { No. of observed reflections } \\
{[I>2 \sigma(I)]}\end{array}$ & 7792 & 5616 \\
\hline$R_{\text {int }}$ & 0.0192 & 0.0359 \\
\hline$R_{\sigma}$ & 0.0134 & 0.0303 \\
\hline
\end{tabular}




\begin{tabular}{lll}
$(\sin \theta / \lambda)_{\max }\left[\AA^{-1}\right]$ & 0.738 & 0.738 \\
Refinement & 0.0300 & 0.0387 \\
$R\left[F^{2}>2 \sigma\left(F^{2}\right)\right]$ & 0.0747 & 0.0929 \\
$w R\left(F^{2}\right)$ & 1.026 & 1.043 \\
$S$ & 8572 & 6949 \\
No. of reflections & 361 & 311 \\
No. of parameters & 8 & 0 \\
No. of restraints & $0.621,-0.620$ & $1.282,-0.741$ \\
$\Delta \rho_{\max }, \Delta \rho_{\text {min }}\left(\mathrm{e} \AA^{-3}\right)$ & & \\
\hline
\end{tabular}


Table S2. Bond distances and angles for the metal-organic framework $[\mathrm{Zn}(\mathrm{bpdc})(\mathrm{L} 2)]_{n} \cdot n \mathrm{DMF}(\mathbf{T M U}-\mathbf{6 7})$

\begin{tabular}{|c|c|c|c|c|c|}
\hline Zn1-N1 & $2.1237(10)$ & $\mathrm{N} 1-\mathrm{Zn} 1-\mathrm{N} 4^{\mathrm{i}}$ & $168.00(4)$ & $\mathrm{N} 4^{\mathrm{i}}-\mathrm{Zn} 1-\mathrm{O} 4^{\mathrm{ii}}$ & $84.64(4)$ \\
\hline $\mathrm{Zn} 1-\mathrm{N} 4^{\mathrm{i}}$ & $2.1525(10)$ & $\mathrm{N} 1-\mathrm{Zn} 1-\mathrm{O} 2$ & $97.22(4)$ & $\mathrm{N} 4^{\mathrm{i}}-\mathrm{Zn} 1-\mathrm{O} 5^{\mathrm{iii}}$ & $97.70(4)$ \\
\hline $\mathrm{Zn} 1-\mathrm{O} 2$ & $2.0289(9)$ & $\mathrm{N} 1-\mathrm{Zn} 1-\mathrm{O} 4^{\mathrm{ii}}$ & $83.78(4)$ & $\mathrm{O} 2-\mathrm{Zn} 1-\mathrm{O} 4^{\mathrm{ii}}$ & $126.75(4)$ \\
\hline $\mathrm{Zn} 1-\mathrm{O} 4^{\mathrm{ii}}$ & $2.0712(9)$ & $\mathrm{N} 1-\mathrm{Zn} 1-\mathrm{O}^{\mathrm{iii}}$ & $92.29(4)$ & $\mathrm{O} 2-\mathrm{Zn} 1-\mathrm{O}^{\mathrm{iii}}$ & $102.02(4)$ \\
\hline $\mathrm{Zn} 1-\mathrm{O} 5^{\mathrm{iii}}$ & $1.9859(9)$ & $\mathrm{N} 44^{\mathrm{i}} \mathrm{Zn} 1-\mathrm{O} 2$ & $87.21(4)$ & 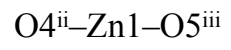 & $131.21(4)$ \\
\hline
\end{tabular}

Superscripts $\mathrm{i}-\mathrm{iii}$ indicate atoms generated by the following symmetry operations: (i) $x+1, y, z+1$; (ii) $-x+2, y-1 / 2$, $-z+1 \frac{1}{2}$ and (iii) $x-1,-y+1 / 2, z+1 / 2$.

Table S3. Bond distances and angles for the metal-organic framework $\left[\mathrm{Zn}_{2}(\mathrm{bdc})_{2}(\mathrm{~L} 2)_{2}\right]_{n} \cdot 2 n \mathrm{DMF}(\mathrm{TMU}-$ 68)

$\begin{array}{cccccr}\mathrm{Zn} 1-\mathrm{N} 1 & 2.1332(15) & \mathrm{N} 1-\mathrm{Zn} 1-\mathrm{N} 4^{\mathrm{i}} & 174.87(6) & \mathrm{N} 4-\mathrm{Zn} 1-\mathrm{O} 3^{\mathrm{ii}} & 89.37(6) \\ \mathrm{Zn} 1-\mathrm{N} 4^{\mathrm{i}} & 2.1314(15) & \mathrm{N} 1-\mathrm{Zn} 1-\mathrm{O} 2 & 91.20(6) & \mathrm{N} 4^{\mathrm{i}}-\mathrm{Zn} 1-\mathrm{O} 4 & 86.38(6) \\ \mathrm{Zn} 1-\mathrm{O} 2 & 2.0269(13) & \mathrm{N} 1-\mathrm{Zn} 1-\mathrm{O} 3^{\mathrm{ii}} & 91.55(6) & \mathrm{O} 2-\mathrm{Zn} 1-\mathrm{O} 3^{\mathrm{ii}} & 131.58(6) \\ \mathrm{Zn} 1-\mathrm{O} 3^{\mathrm{ii}} & 2.0356(13) & \mathrm{N} 1-\mathrm{Zn} 1-\mathrm{O} 4 & 88.50(6) & \mathrm{O} 2-\mathrm{Zn} 1-\mathrm{O} 4 & 133.25(6) \\ \mathrm{Zn} 1-\mathrm{O} 4 & 2.0489(14) & \mathrm{N} 4-\mathrm{Zn} 1-\mathrm{O} 2 & 91.96(6) & \mathrm{O}^{\mathrm{ii}}-\mathrm{Zn} 1-\mathrm{O} 4 & 95.15(6)\end{array}$

Superscripts $\mathrm{i}-\mathrm{ii}$ indicate atoms generated by the following symmetry operations: (i) $x-1 / 2,-y+1 / 2, z-1 / 2$ and (ii) $x$, $y+1, z$. 

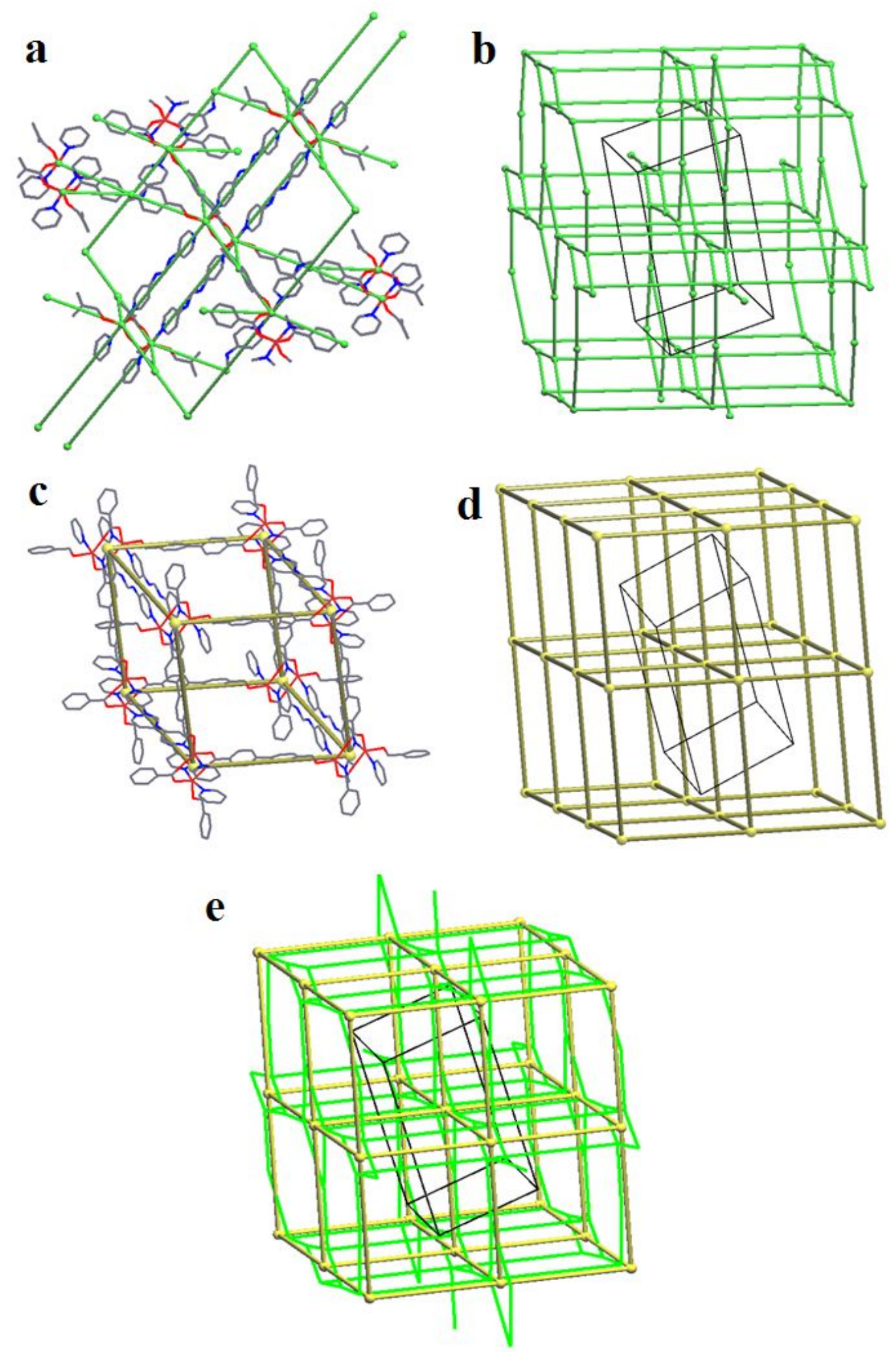

Figure S1. a, b) TMU-67, represented as single net in standard description as $(3,5)$-c fet c, d) TMU-67, represented as single net in cluster description as 6-c pcu 
(notice two parallel “double-bridged" edges) and e) Relation between fet (green) and pcu (yellow) for TMU-67 

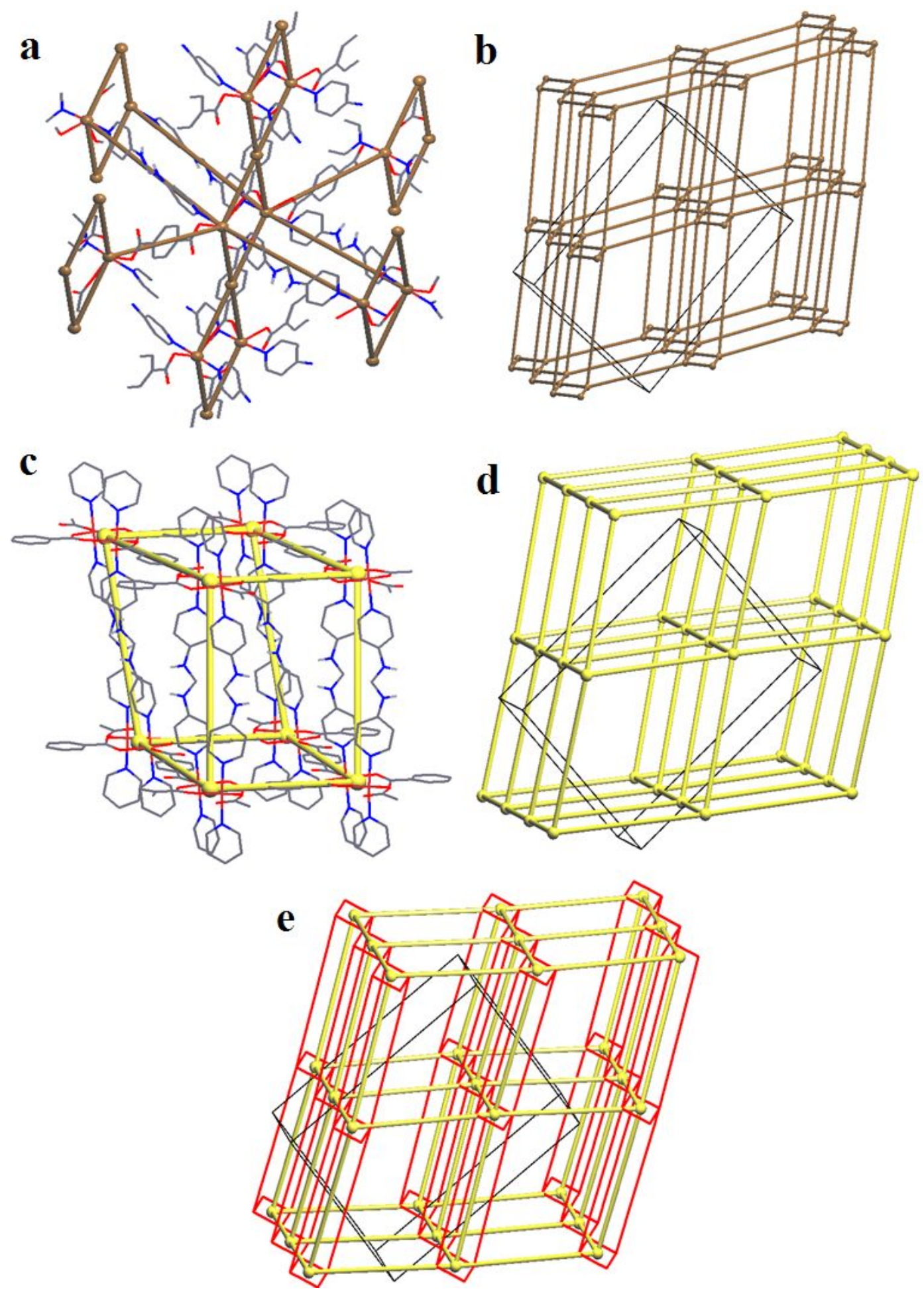

Figure S2. a, b) TMU-68, represented as single net in standard description as (4,5)-c sqc65, c, d) TMU-68, represented as single net in cluster description as 6-c pcu (notice four parallel "double-bridged" edges) and e) Relation between sqc65 (red) and pcu (yellow) for TMU-68 


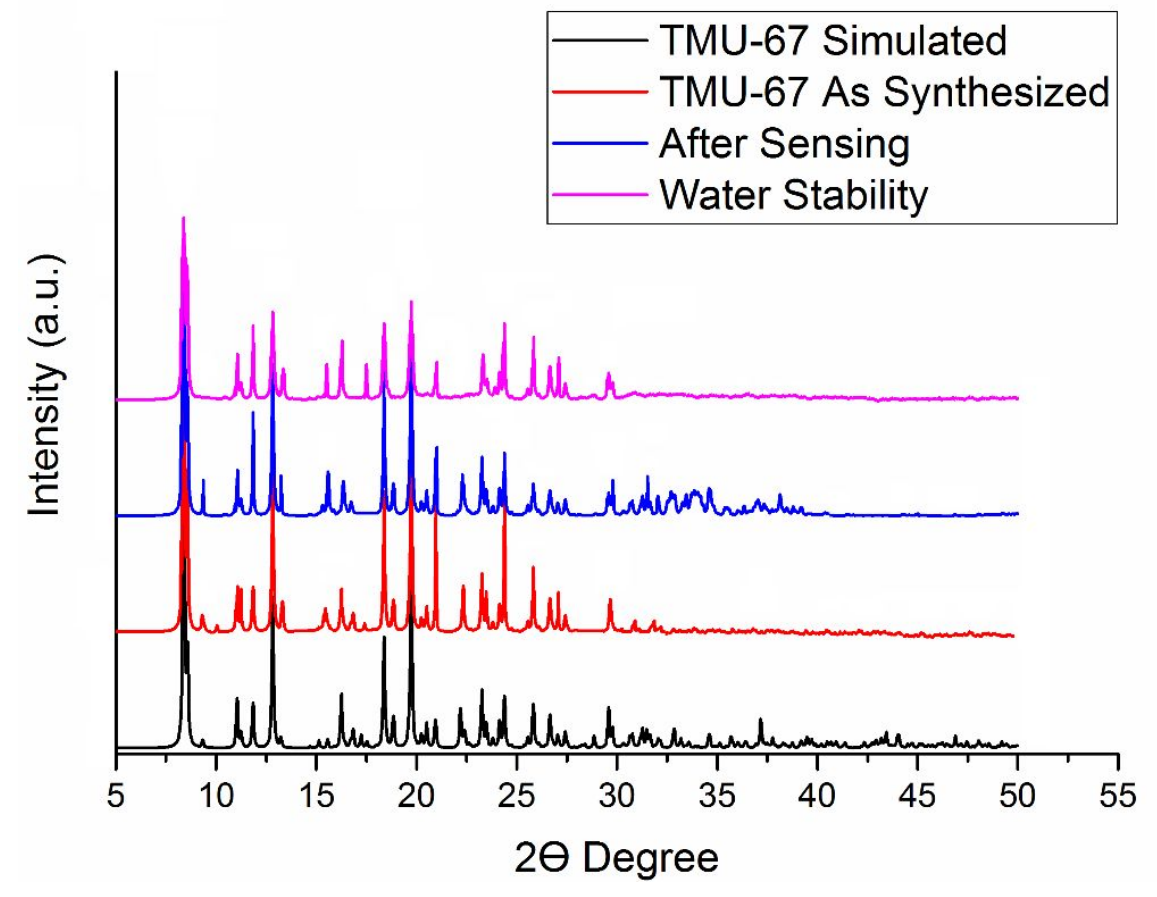

Figure S3. PXRD patterns of simulated, as-synthesized, after sensing of dihydrogen arsenate $\mathrm{H}_{2} \mathrm{AsO}_{4}{ }^{-}$and after soaking in water for microcrystalline TMU-67. 


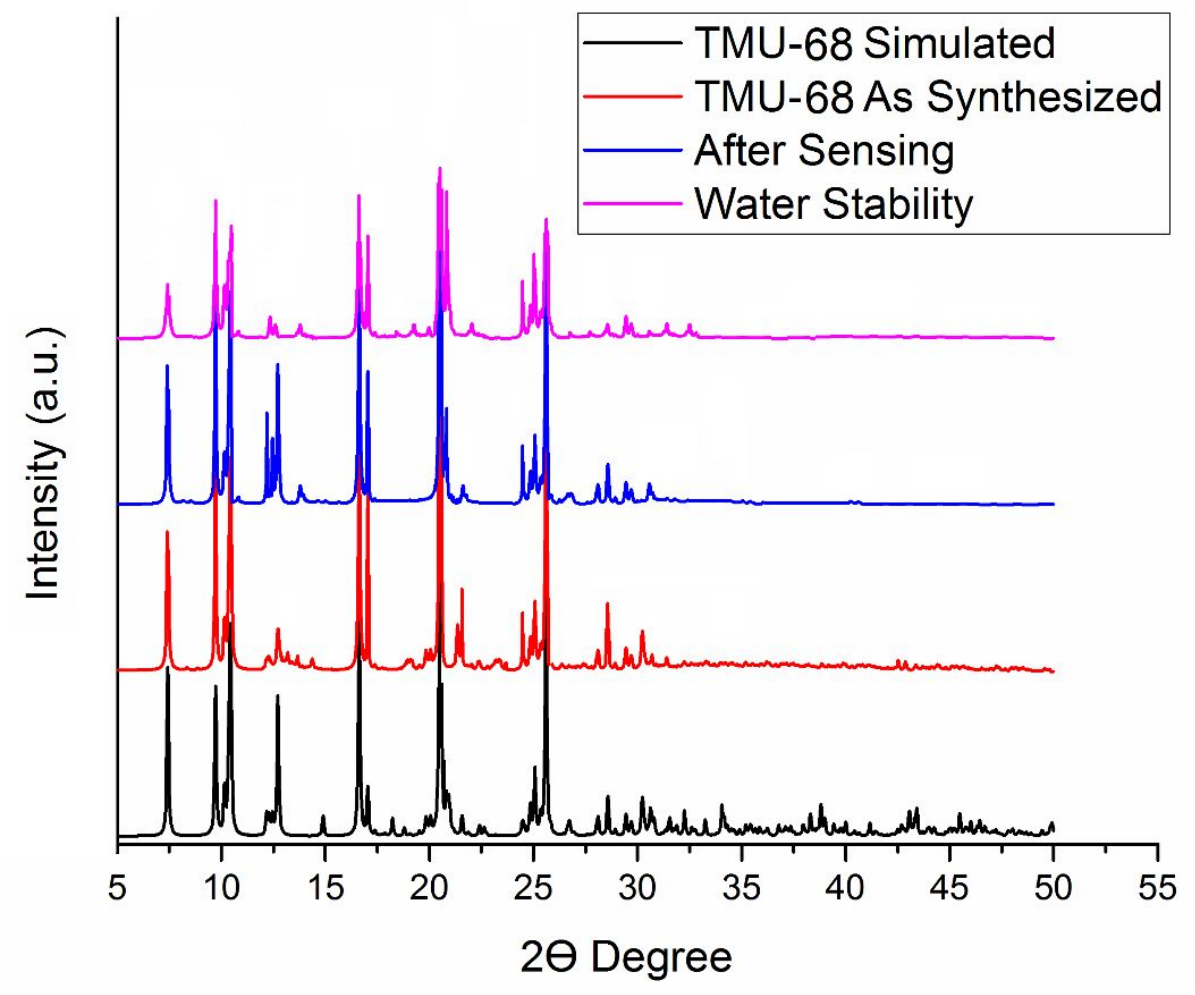

Figure S4. PXRD patterns of simulated, as-synthesized, after sensing of fluoride $\mathrm{F}^{-}$and after soaking in water for microcrystalline TMU-68.

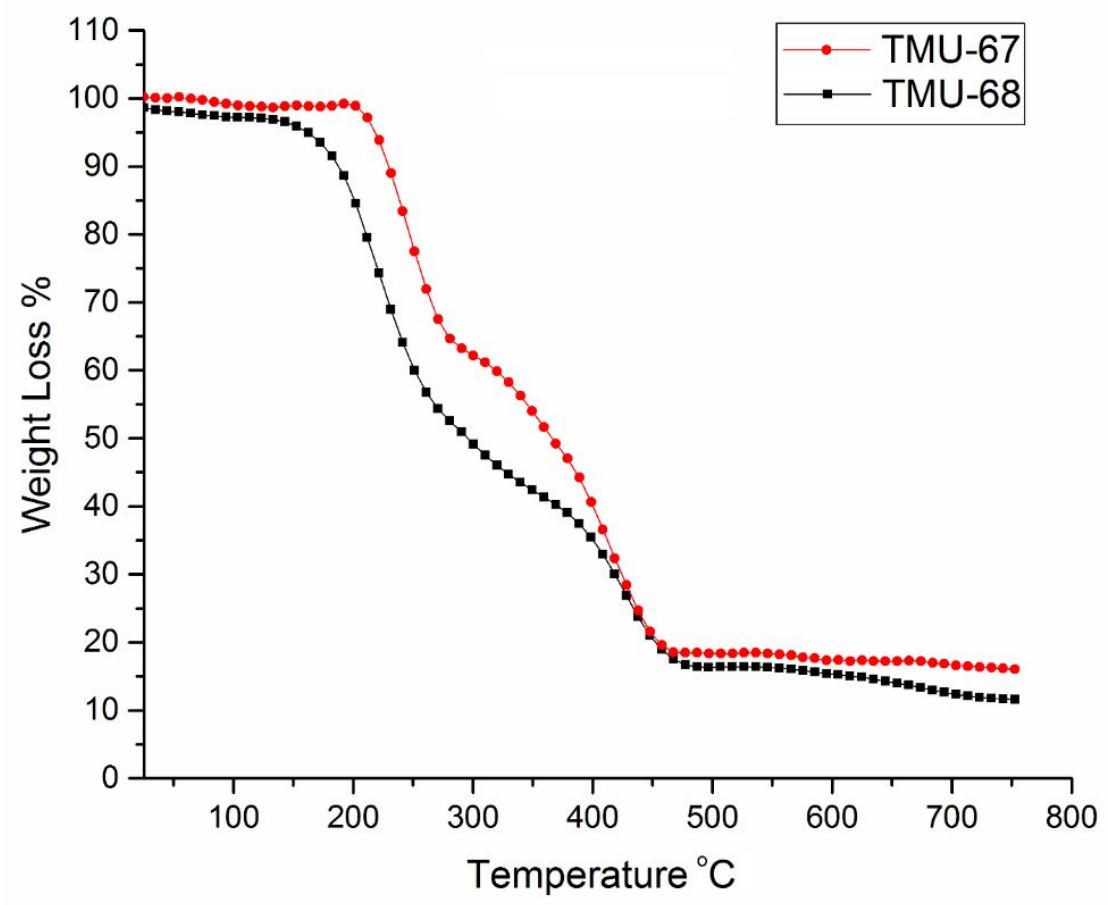

Figure S5. Thermogravimetric analysis of TMU-67 and TMU-68. 


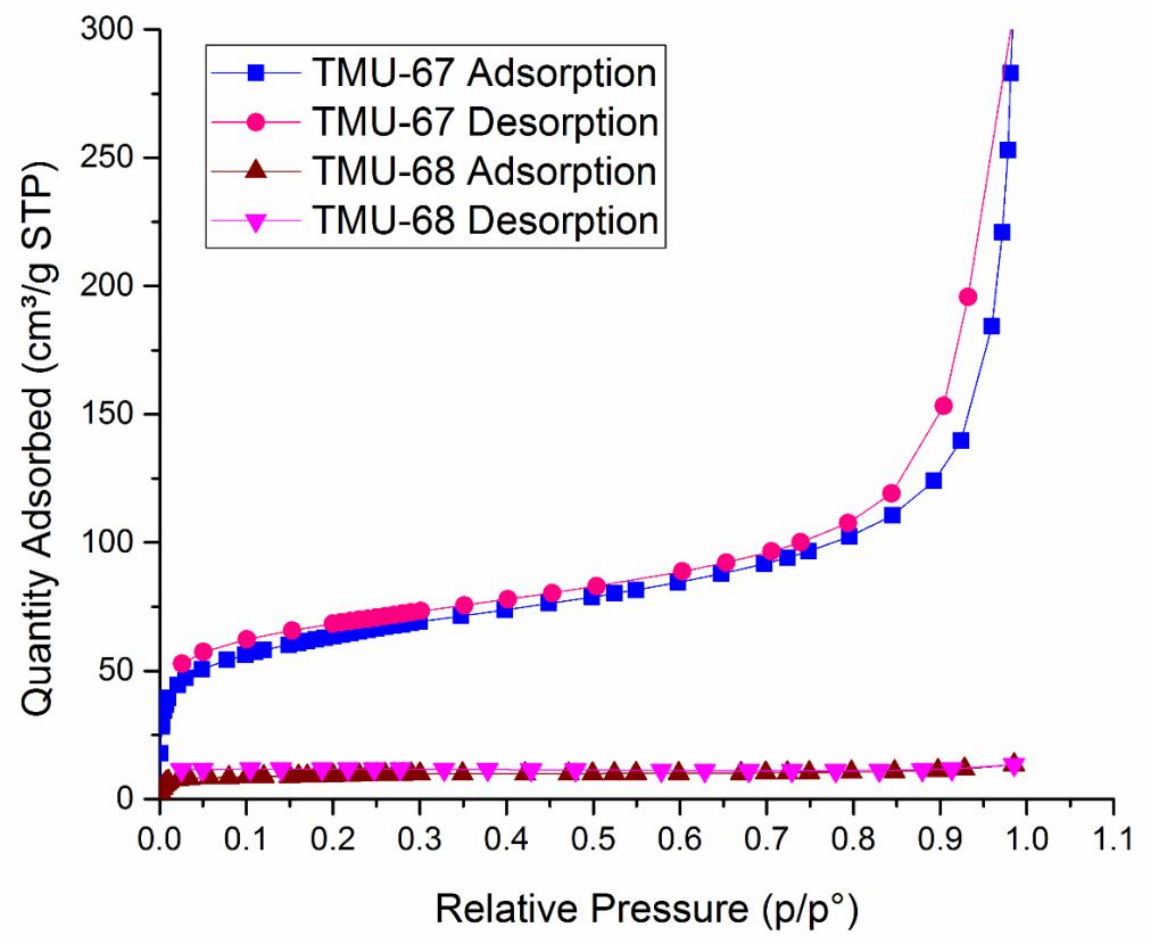

Figure S6. BET analysis of TMU-67 and TMU-68. 
Anion sensing procedure. All the fluorescence experiments were performed preparing a suspension of 3 $\mathrm{mg}$ of grounded activated material (TMU-67 or TMU-68) in $3 \mathrm{~mL}$ of an aqueous solution of the sodium salts of the different anions $\left(\mathrm{F}^{-}, \mathrm{Cl}^{-}, \mathrm{H}_{2} \mathrm{AsO}_{4}^{-}, \mathrm{H}_{2} \mathrm{PO}_{4}^{--}, \mathrm{NO}_{2}^{-}, \mathrm{SO}_{4}{ }^{2-}, \mathrm{HPO}_{4}{ }^{2-}, \mathrm{NO}_{3}^{-}, \mathrm{HAsO}_{4}{ }^{2-}\right.$ or $\mathrm{ClO}_{4}^{-}$), using sonication to facilitate dispersion of the powder. Samples prepared in this way are homogeneous and stable during the tests. All the fluorescence spectra were collected at room temperature, $10 \mathrm{~min}$ after the addition of the target anions. The fluorescence emission were measured at $450 \mathrm{~nm}$ and $430 \mathrm{~nm}$ upon excitation at $350 \mathrm{~nm}$ and $370 \mathrm{~nm}$ for TMU-67 and TMU-68, respectively.

Data analysis have been performed according to the below equation

$$
\frac{I}{I_{0}}=K_{\mathrm{ec}}[\mathrm{A}]+1
$$

in which $I_{0}$ is the fluorescence intensity of a MOF sample soaked in water, $I$ is the fluorescence intensity in presence of the analyte, [A] is the molar concentration of the analyte and $K_{\mathrm{ec}}$ is the enhancement constant $\left(\mathrm{M}^{-1}\right)$. 


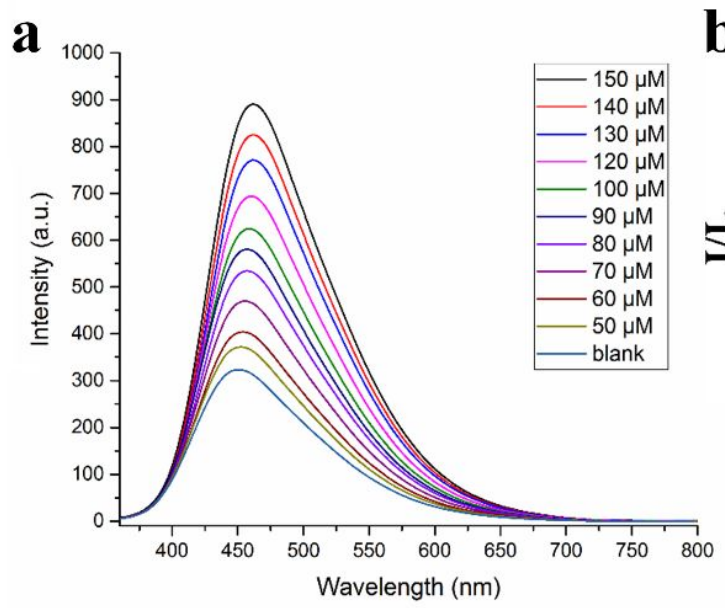

Wavelength $(\mathrm{nm})$

b
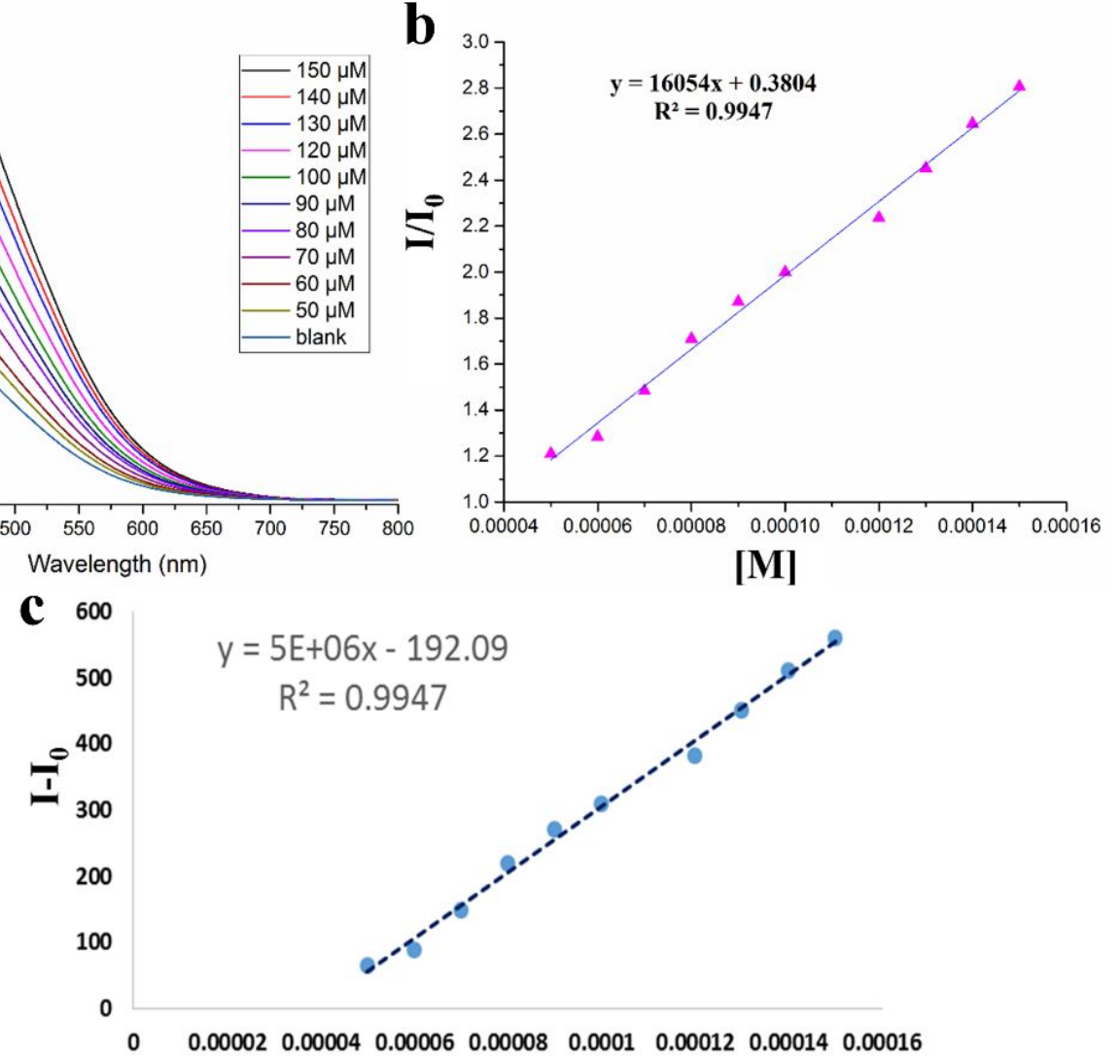

[M]

Figure S7. (a) Fluorescence emission spectra of TMU-67 dispersed in aqueous solutions containing different concentrations of $\mathrm{H}_{2} \mathrm{PO}_{4}^{-}$. (b and c) The corresponding calibration curves. The limit of detection (LOD): $50 \mu \mathrm{M}$ 

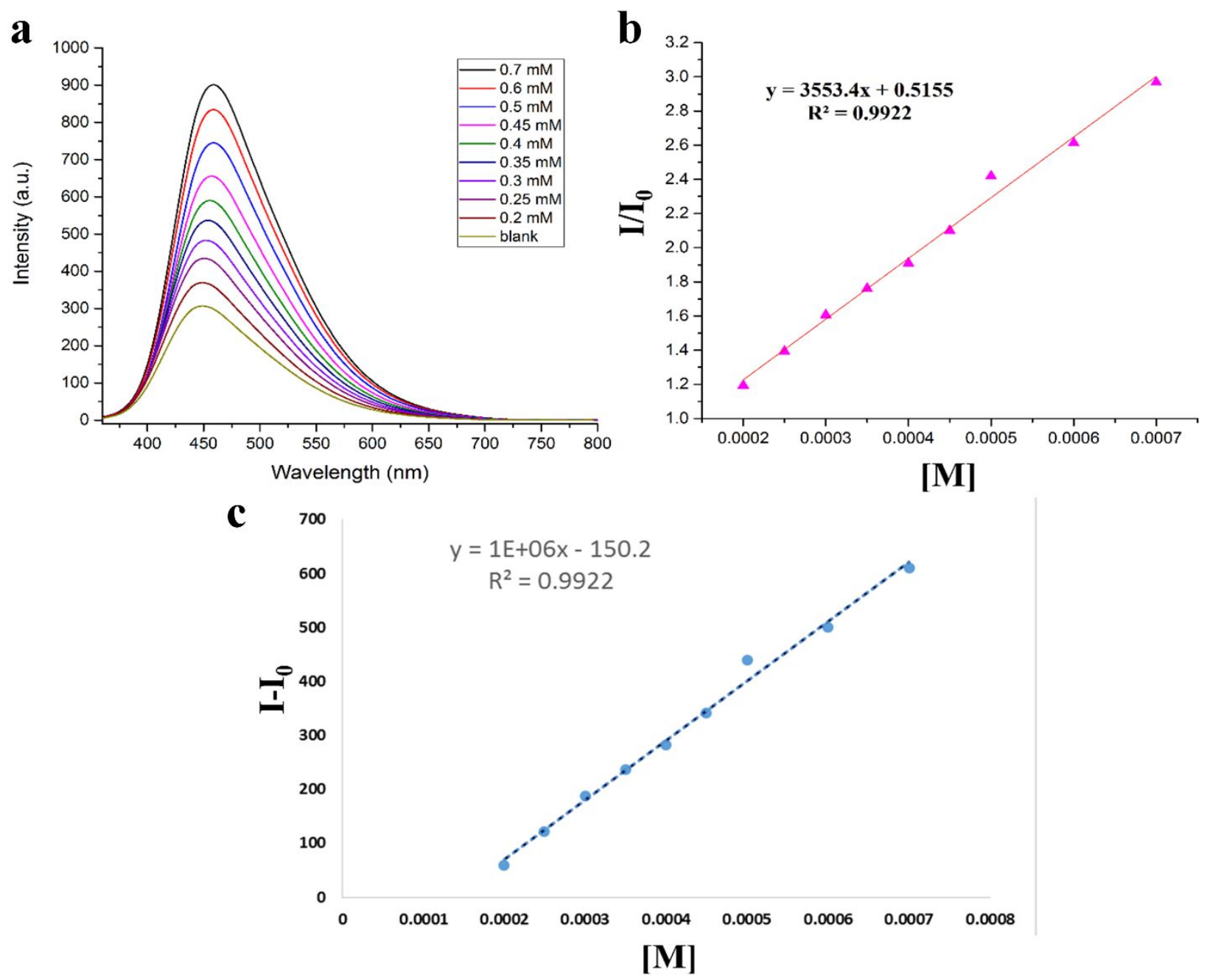

Figure S8. (a) Fluorescence emission spectra of TMU-67 dispersed in aqueous solutions containing different concentrations of $\mathrm{NO}_{2}^{-}$. (b and c) The corresponding calibration curves. The limit of detection (LOD): $0.2 \mathrm{M}$ 


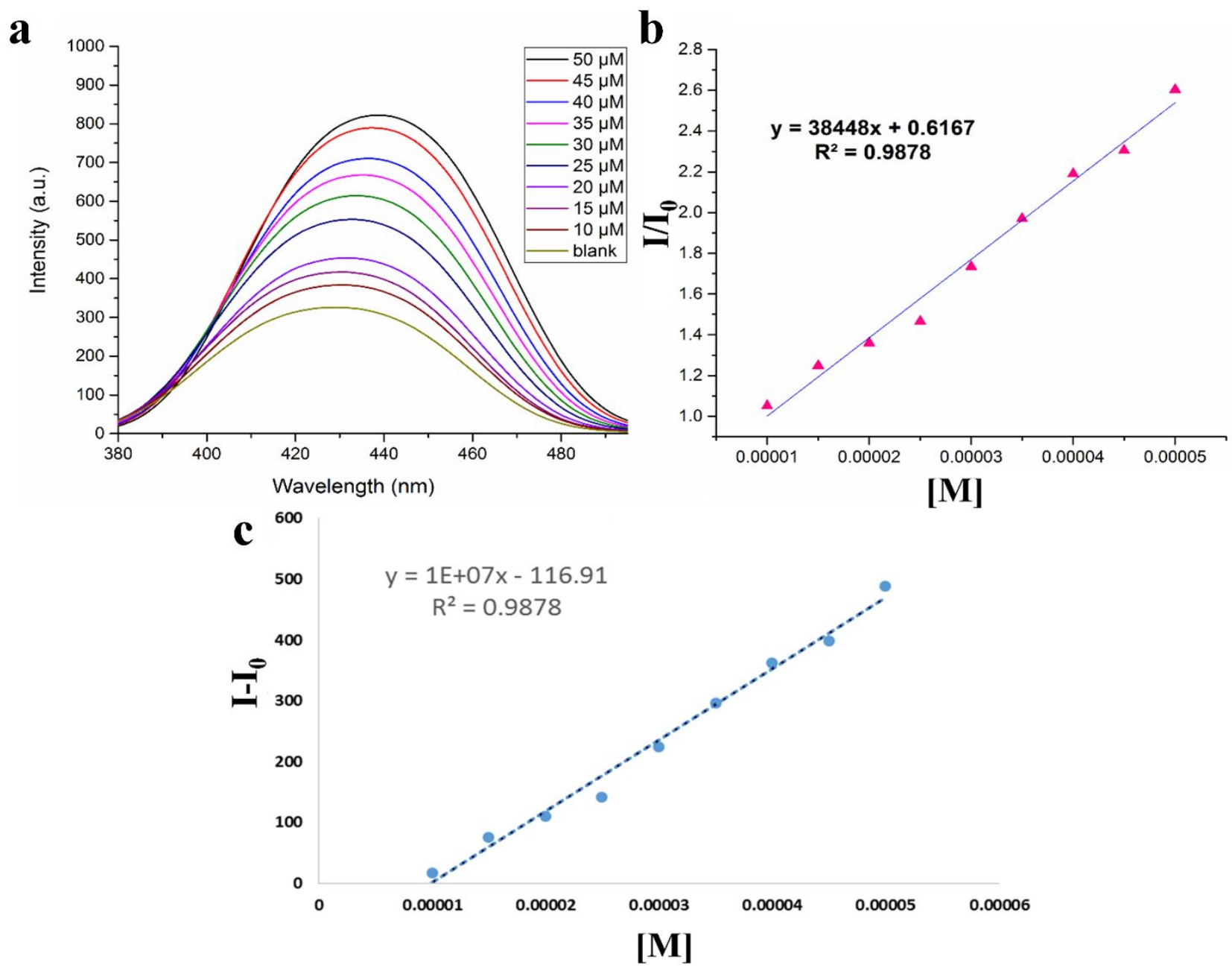

Figure S9. (a) Fluorescence emission spectra of TMU-68 dispersed in aqueous solutions containing different concentrations of $\mathrm{F}^{-}$. (b and $\mathrm{c}$ ) The corresponding calibration curves. The limit of detection (LOD): $10 \mu \mathrm{M}$ 

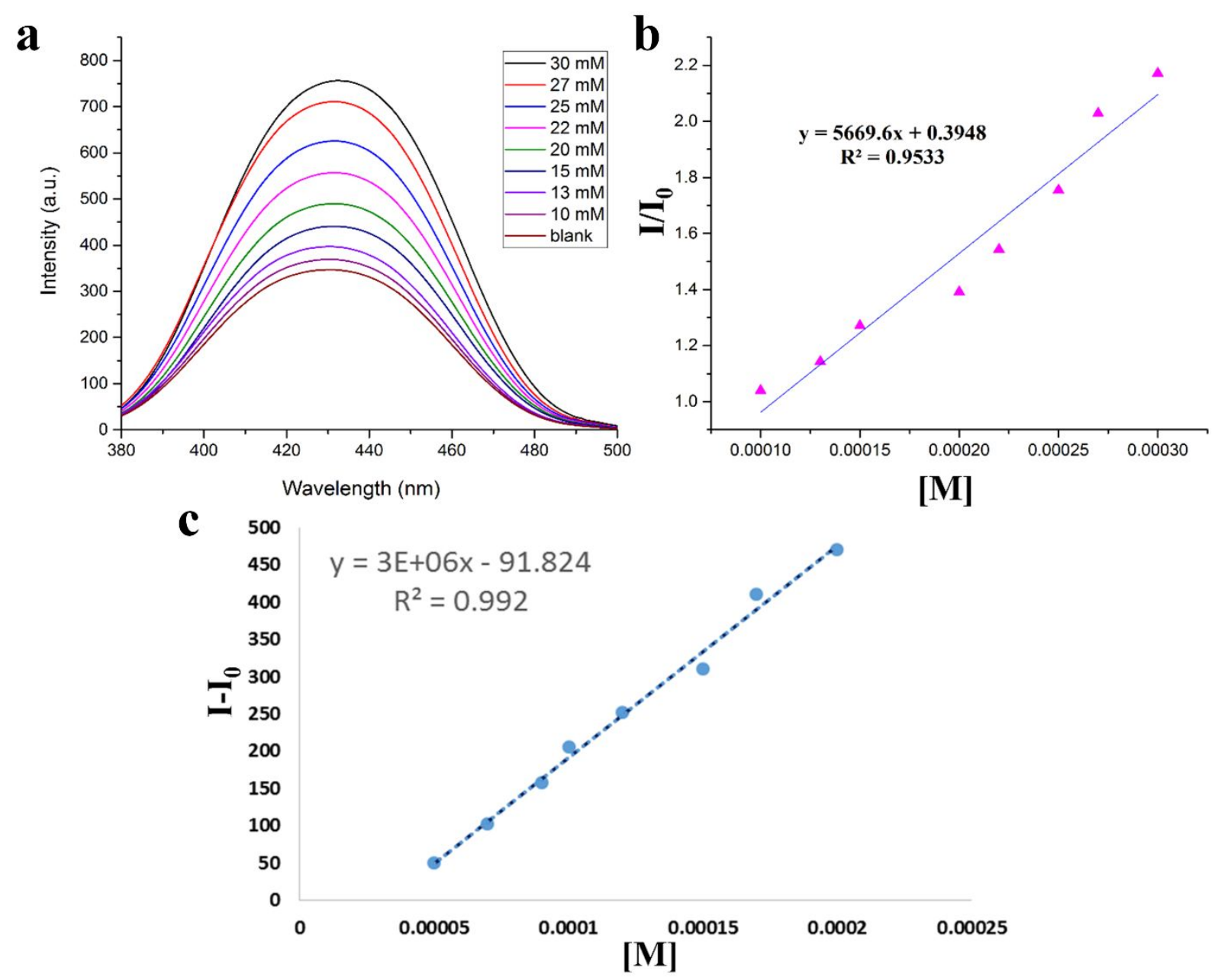

Figure S10. (a) Fluorescence emission spectra of TMU-68 dispersed in aqueous solutions containing different concentrations of $\mathrm{NO}_{2}^{-}$. (b and c) The corresponding calibration curves. The limit of detection (LOD): $10 \mathrm{mM}$ 

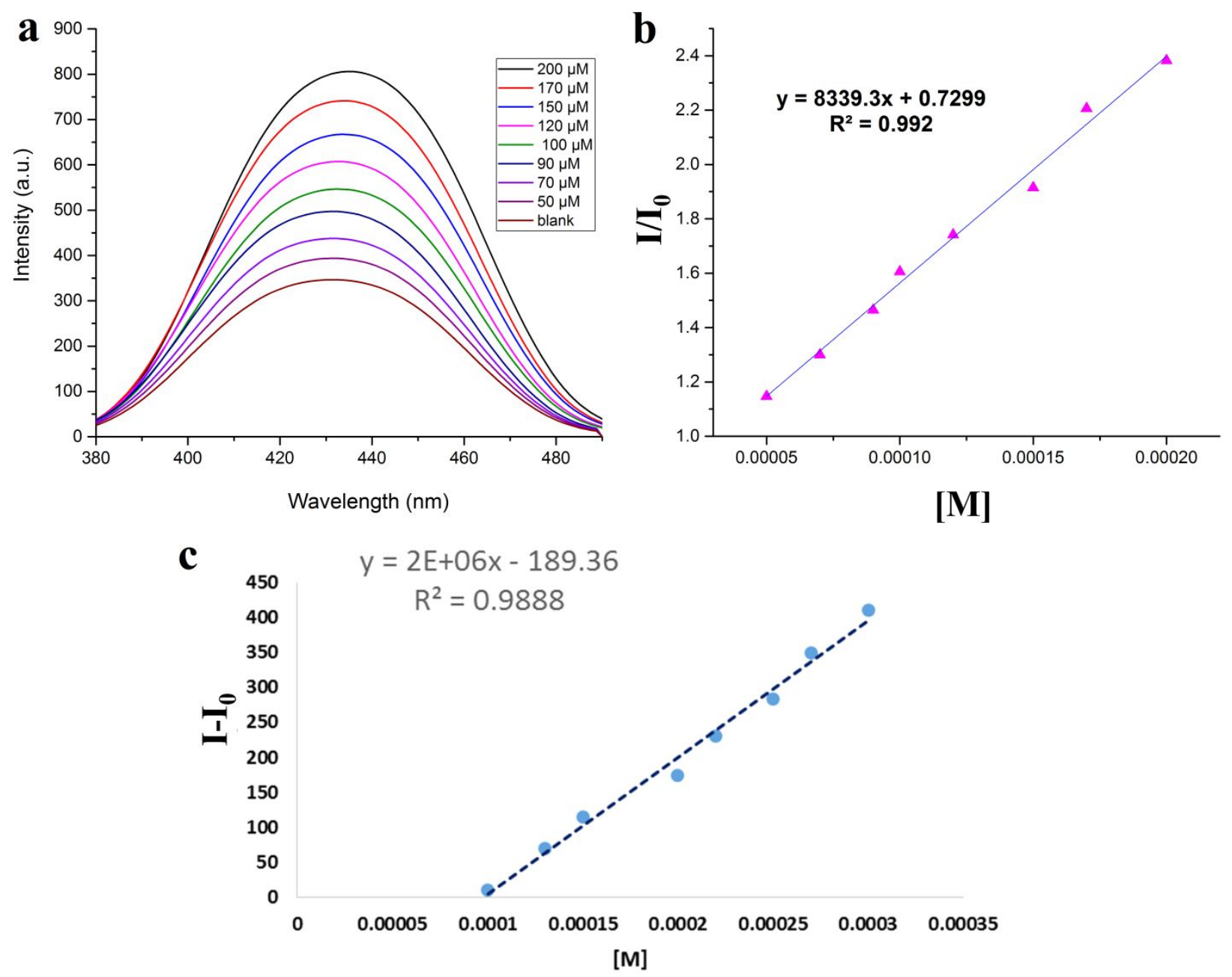

Figure S11. (a) Fluorescence emission spectra of TMU-68 dispersed in aqueous solutions containing different concentrations of $\mathrm{H}_{2} \mathrm{PO}_{4}^{-}$. (b and c) The corresponding calibration curves. The limit of detection (LOD): $50 \mu \mathrm{M}$ 


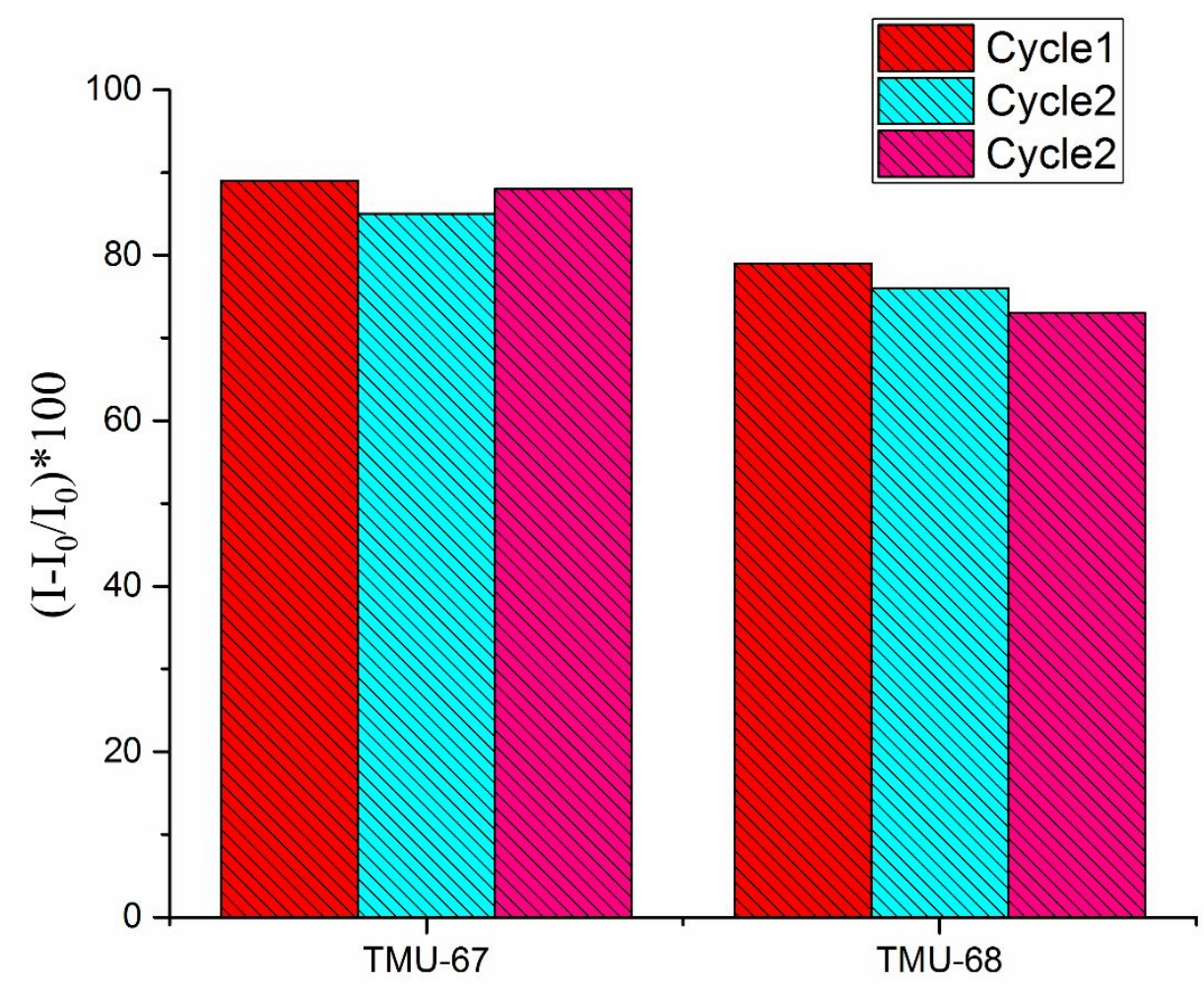

Figure S12. Regeneration and reusing of TMU-67 and 68 for $\mathrm{F}^{-}$and $\mathrm{H}_{2} \mathrm{AsO}_{4}^{-}$sensing.

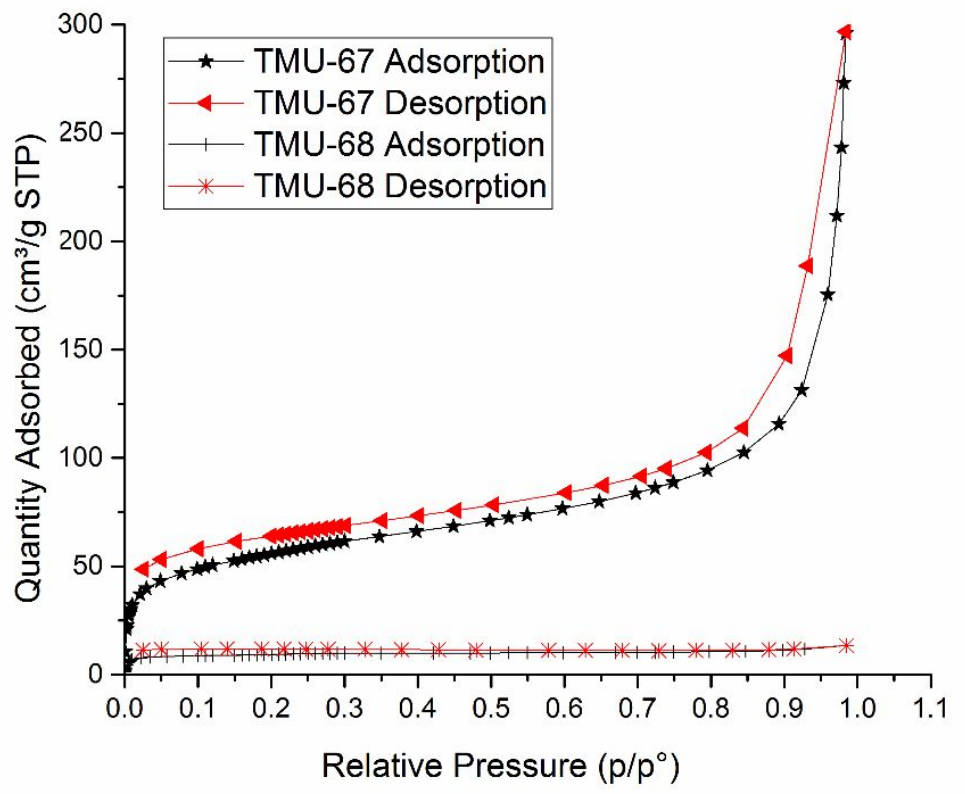

Figure S13: Nitrogen adsorption-desorption isotherms at $77 \mathrm{~K}$ for TMU-67 and $\mathbf{6 8}$ after recycle. 

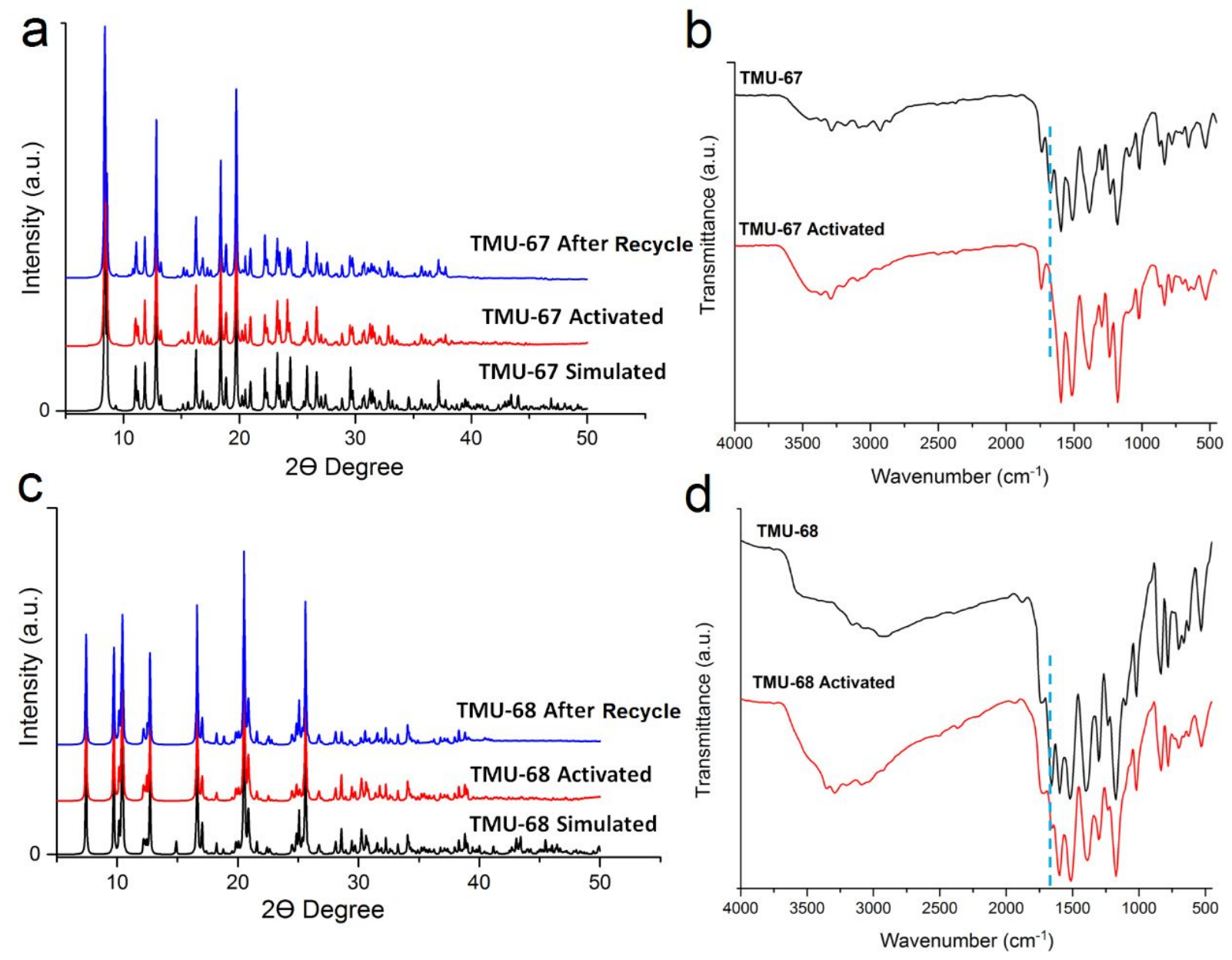

Figure S14. FT-IR spectra of as-synthesized (black) and activated (red) of b) TMU-67 and d) TMU-68 and PXRD patterns of simulated, activated and after recycling of a) TMU-67 and c) TMU-68

(1) Burla, M. C.; Caliandro, R.; Carrozzini, B.; Cascarano, G. L.; Cuocci, C.; Giacovazzo, C.; Mallamo, M.; Mazzone, A.; Polidori, G. Crystal structure determination and refinement viaSIR2014. Journal of Applied Crystallography 2015, 48, 306-309.

(2) Sheldrick, G. M. Crystal structure refinement with SHELXL. Acta Crystallographica Section C: Structural Chemistry 2015, 71, 3-8. 